\title{
What happens to cutaneous and musculoskeletal sequelae of buruli ulcer one to five years after return home to healed patients
}

\begin{abstract}
Buruli ulcer (BU) is an emerging disease caused by Mycobacteriumulcerans ( $\mathrm{Mu})$. It occurs in the form of endemic foci in the tropics (in Africa, America, Asia and Oceania. ${ }^{1}$ Infection with the human immunodeficiency virus (HIV) is a factor that increase this emergence of the disease. ${ }^{2,3}$ Its treatment needs using of specific antibiotics, but also plastic and /or orthopedic surgical methods. ${ }^{3-5}$ If the disease is mutilating by itself, its taking care is not less mutilating, in some cases. However, after healing, there are capacity limitations and participation restrictions that occur in a significant number of patients. ${ }^{6-9}$ They can range from a simple limitation to ankylosis, or from a loss of substance to an amputation. These are sometimes cancerous lesions, especially after a retreat of at least 5 years. ${ }^{10}$ Despite those numerous problems, in Benin patients who are cured return to their homes and are not often reviewed for an assessment of their future. This study aims to examine the becoming of the cutaneous and musculoskeletal sequelae of former UB patients one to five years after returning home.
\end{abstract}

Keywords: buruli ulcer, becoming, skin sequelae, musculosquletics, healed patients
Volume 2 Issue 3 - 2017

EH Alagnidé, ',2 H Azanmasso,' DD Niama

Natta,' GM Houngbédji, ${ }^{1,2}$ TG Kpadonou ${ }^{1,2}$

'Department of Physical and Rehabilitation Medicine, National Teahing Hospital, Benin

${ }^{2}$ Faculty of Sciences of Health, Benin

Correspondence: Toussaint G Kpadonou, Department of Physical and Rehabilitation Medicine, National Teahing Hospital, Benin,Tel 002299758892, Email kpadonou_toussaint@yahoo.fr

Received: June 28, 2017 | Published: December 08, 2017

\section{Patients and method}

\section{Patients}

The study's population consisted of patients with BU, treated, monitored and reported to be cured at the Allada Buruli Ulcer Screening and Treatment Center (BUSTC) from 2005 to 2009. Sampling was carried out taking into account criteria listed below:

Inclusion criteria: Were included in the study, patients who had:

i. Be detected, cared for and declared cured at the allada BUSTC from January 2005 to December 2009,

ii. An address found in the BUSTC database and/or identified by the community relays,

iii. During the period of study, a residence in Benin within a radius of $100 \mathrm{~km}$ at most of the allada BUSTC (geographical area of the BUSTC of allada)

iv. Be found during the study's period

v. Given their informed consent to participate to the study.

\section{Non-inclusion criteria}

Patients with cutaneous or musculoskeletal abnormalities identified but recognized by the patient or his/her entourage in connection with:

i. A history of trauma or rheumatologic lesions that occurred prior to Buruli ulcer disease.

ii. Neurological complications of medical conditions (diabetic foot, hemiplegia due to arterial hypertension)

\section{Method}

\section{Type of study}

This is a cross-sectional and descriptive study that took place from January to July 2010 in the geographical area of the BUSTC of Allada in the Atlantic department of Benin.

\section{Progress}

From the database obtained at the Allada BUSTC we have identified 347 patients who were followed up and declared cured during the period from January 2005 to December 2009. Assisted by the BU community relays and usually an appointment at their home two hundred and forty- four (244). Patients meeting above criteria were seen at home.

\section{Study's variables}

Aspect of wound healing

Fibro-retractile: scar stretched, without elevation of the skin or whose elevation is very little marked.

Hypertrophic/keloidal: elevated scar and/or in the form of an elongated bead provided with extensions or root digusions

Good: In the absence of hypertrophic, keloids or retractile scars.

\section{Musculoskeletal disorders}

Amyotrophy: It was said to be present when the difference between the circumference of the healthy limb and the affected limb was greater than or equal to $1 / 20$ of the circumference of the limb healthy.

Stiffness: It has been defined as a reduction of at least $10 \%$ of the articular mobility at the articulation(s) of the member concerned, after a comparative goniometry.

Paresis: It was defined as a muscular force of muscular chains of the affected limb, less than or equal to 4 according to the rating of the muscular testing by the Medical Research Council.

\section{Data processing and analysis}

Data was entered in the Microsoft Office Excel 2007 software. The statistical analysis was done by EPI info version 3.4.3 software. 
Proportions of different modalities of the variables studied were calculated. The chi-square statistical test (X2) was used to study the influence of a given qualitative variable on another data item. The difference was said statistically significant when $\mathrm{p}<0.05$.

\section{Ethical considerations}

This survey was authorized by the National Program for the Control of Leprosy and Buruli Ulcer (NPCLBU). The information was collected after informed consent of patients and/or their parents. Strict respect for anonymity, and medical confidential were observed.

\section{Results}

\section{Patient characteristics}

Age and sex: The average age of patients in this study was 8 years with the extremes of 6 and 89 years. $50.4 \%$ of the patients were male. The sex ratio was 1.01 .

Clinical and therapeutic aspects (at entry into the program): At entry, 152 patients $(62.3 \%)$ were at a decaying ulcer stage; 75 patients $(30.7 \%)$ were at a non-ulcerated stage (plaque, nodule, papule or edema) in the end at the scar stage for the remaining $7 \%$ of patients. Lesions were mostly found in pelvic limbs (53.7\%), thoracic limbs(31.6\%) and trunk(8.6\%). Table 1 presents the clinical and therapeutic characteristics of the patients.

Table I Distribution of patients by clinical and therapeutic characteristics

\begin{tabular}{|c|c|c|}
\hline & Number & Percentage (\%) \\
\hline \multicolumn{3}{|l|}{ Seat of Lesions } \\
\hline Pelvic limb & $13 \mid$ & 53,7 \\
\hline Thoracic limb & 77 & 31,6 \\
\hline Trunk & 21 & 8,6 \\
\hline Neck & 4 & $\mathrm{I}, 6$ \\
\hline Multiple seat & 8 & 3,3 \\
\hline Face & 3 & 1,2 \\
\hline Total & 244 & 100,0 \\
\hline \multicolumn{3}{|l|}{ Stage of initial lesion } \\
\hline Decaying ulcer & 152 & 62,3 \\
\hline Not ulcerated & 75 & 30,7 \\
\hline scar & 17 & 7,0 \\
\hline Total & 244 & 100,0 \\
\hline \multicolumn{3}{|l|}{ Treatment received } \\
\hline medicated & 47 & 19,3 \\
\hline Medical-Surgical & 49 & 20,0 \\
\hline Medico-chirurgical and rehabilitation & $|3|$ & 53,7 \\
\hline Traditional & 17 & 7,0 \\
\hline Total & 244 & 100,0 \\
\hline
\end{tabular}

\section{Patients physical becoming}

Wound healing was fibro retractile in $62.3 \%(\mathrm{n}=152)$, hypertrophi/ keloid in $32.4 \%(\mathrm{n}=79$, bout neuro-locomotor level, $75.3 \%$ of the patients $(n=165)$ had atrophy of the affected limb, $65.2 \%$ of the patients $(n=159)$ had sensitivity disorders. Six (6) patients $(2.5 \%)$ were amputated, five of them (5) were at the pelvic limbs. None of these amputees were paired. Four of amputees used crutches. Table 2 presents the different outcome parameters studied in these patients.

Table 2 Distribution of patients by clinical fate

\begin{tabular}{lll}
\hline & Number & Percentage (\%) \\
\hline Type of scar & 152 & 62,3 \\
Fibro-retractile scar & 43 & 17,6 \\
Hypertrophic scar & 36 & 14,8 \\
Keloidscar & 13 & 5,3 \\
Good healing & 244 & 100,0 \\
Total & & \\
Neuro-locomotordisorders & & 75,3 \\
Amyotrophy of affectedlimb & 165 & 62,5 \\
Sensitivity disorders & 159 & 35,6 \\
Joint stiffness & 78 & 35,1 \\
Muscle paresis & 77 & 2,5 \\
Amputation of limb & 6 &
\end{tabular}

\section{Factors associated with the physical becoming of patient}

Factors associated with the type of scar: The treatment received by the patients had a significant influence on the scar secondary to the BU lesion $(\mathrm{p}=6.10-19)$. As for the initial lesion, it did not significantly influence the type of scar. Table 3 presents the distribution of patients according to the type of scar, the treatment received and the initial lesion.

Factors associated with neuro-locomotor disorders: They are presented in Tables 4, 5 and which show that the treatment received by the patients had an influence on the various neuro-orthopedic sequelae whereas the initial lesion type had no influence on these sequelae.

\section{Discussion}

The distribution of patients by age showed that $\mathrm{BU}$ is a condition of any age (6 to 89 years). The average age of patients was 8 years and the vast majority, $57 \%$, was under 15 years of age. Children were therefore the most exposed. This result can be explained by the almost constant use of waterways during games by children. Similarly, the frequent neglected wounds of children during these domestic activities constitute entrance doors of the Mu. Several authors have produced similar results and explanations. ${ }^{6,11-13}$ The low immunity of patients has also been mentioned., ${ }^{9,14}$ The proportion of male subjects in our series was $50.4 \%$, with a sex ratio of 1.01 . Subjects of both sexes were thus achieved in a comparable manner. Authors have reached the same conclusions. ${ }^{12,15,16}$ Barker $^{17} \&$ Kadio $^{18}$ reported higher rates among girls than boys in Côte d'Ivoire. Van der Werf. ${ }^{19}$ on the contrary reported higher rates among men than women in Ghana. 
In terms of physical and functional becoming, according to the aspect of the healing of the lesions, table 2 shows that $62.3 \%$ of the patients presented fibro-retractile healing. The phenomena of scarring of the lesions in $\mathrm{BU}$ are similar to those observed in burns. The high collagen content of black skin may contribute to this spontaneous tendency to fibrous and retractile scarring. These same findings have been reported in the literature. ${ }^{1,9}$ Hypertrophic scars or keloids were observed in $32.4 \%$ of cases $(\mathrm{n}=79)$. This result is similar to that of Lehman et al. ${ }^{1}$ Keloids are today the biggest fear of the cosmetic surgeon. Six (6) patients in the series, meaning 2.5\%, had limb amputation, as reported in table 2. Other authors have also had amputation cases with proportions of $4-5 \%$ in their series..$^{20,21}$ This result may be related to the sometimes very late discovery of some patients with extensive and severe ulcer lesions. The loss of a part of the body is the most feared thing both by the patients and by the practitioners themselves. These amputations were often of cleanliness and were decided only for very extensive and severe bone lesions. ${ }^{22}$

The levels of amputations observed are various. Five (5) patients had amputation to the pelvic limb. The prevalence of BU lesions to pelvic limbs would explain this distribution of the amputation level. None of the amputees had prosthesis. These results illustrate rehabilitation problems faced by these former patients. These include economic, socio-cultural, human resource and equipment problems. There is no doubt that this situation hampers the follow-up of these former patients after healing.

Table 2 shows that three out of four patients (75.3\%) had atrophy of the affected limb, 35.6\% had joint stiffness, $35.1 \%$ had paresis and $65.2 \%$ had cutaneous hypoesthesia. There is a causal relationship between stiffness, amyotrophy and paresis. This large percentage of post BU muscular atrophy also accounts for all the severity of BU sequelae. This is evidence of BU muscle involvement related to the action of $\mathrm{Mu}$ mycolactone..$^{23}$ Prolonged resting of the muscles of the affected limb certainly has its place in the explanation of the occurrence of these neuro-locomotor disorders. Currently, it is recognized that the major problem caused by BU is sequelae and disability. Most authors agree on the importance of the sequelae resulting from $\mathrm{BU}$, but there is little data in the literature. The evaluation of the management of BU must therefore take into account the presence or not of these sequelae. ${ }^{1}$

In our study, $35.6 \%$ of patients showed joint stiffness. Functional rehabilitation, although insufficient, may have contributed to the fact that not all of the exposed patients had this joint stiffness. However, this rate remains higher than that of Lehman et al. ${ }^{1}$ who found that $25 \%$ of patients with BU had sequelae and disabilities.
This high rate of stiffness could be related to the inadequate use of functional rehabilitation techniques but also to time. Indeed, patients once declared cured and returned home do no longer rehabilitate maintenance skills. The limitations of pre-existing participation in the center persist or worsen if the mobility limitations are not used. At the same time, Kanga et al. ${ }^{8}$ noted that functional sequelae were present only in $13 \%$ of patients during a survey of the epidemiological aspects of BU in Ivry Coast in 2001. But this study took into account patients with end of their treatment and not patients recovered years after their return home. $35.1 \%$ of patients $(\mathrm{n}=77)$ had paresis. This is the result of multiple attacks in BU. These injuries are cutaneous, joint, muscular and/or bone. Is this paresis noted in patients related to the primary involvement of muscles by BU or is it related to joint stiffness or amyotrophy? We believe that all this is linked.

On the neurological level, $65.2 \%$ of the patients in the study $(n=159)$ presented sensitivity disorders such as cutaneous hypoesthesia. In $\mathrm{BU}$, destruction of nerve endings probably by mycolactone is early. This decaying ulcer destroys the entire skin. Regeneration occurs with a deficit of innervation. The skin undergoes a major rearrangement leading to fibrous, retractile and hypertrophic scarring which no longer allows a good innervation of this new skin. From all the above, we can say that all patients heal with unsightly sequelae. These sequelae range from the simple scar to amputations, to the limitations of movements. All patients are concerned, so it is urgent that in the studies on the occurrence of the sequelae of UB, authors insist on the unsightly aspect of these scarring lesions. Indeed, according to Knipper "if aestheticsis already function, the function should be aesthetic". ${ }^{4}$ All these limitations of capacity are sources of enormous psychological, social and economic problems. For example, previous studies report impaired quality of life in Buruli ulcer patients compared to healthy subjects. ${ }^{24}$ Similarly, in these patients, anxio-depressive behaviors are noted in a context of family rejection. ${ }^{25}$

Table 3 shows that the initial lesion type was not determinant in the outcome of patients' physical outcome $(\mathrm{p}=0.71)$. However, whether the type of scar carried by these patients or their neuro-orthopedic deformations was significantly influenced by the type of treatment received (Tables 4) (Table 5) (Table6). These findings may be due to the application of routine protocols in the management of these patients with Buruli ulcer. Indeed, in Benin, unlike the management of other conditions that is conditioned by the financial possibilities of the patient, Buruli ulcer is supported almost entirely by a national program. What would have been the outcome of these patients without this program?

Table 3 Patient distribution according to the type of scars according to the initial lesion and the previous treatment

\begin{tabular}{|c|c|c|c|c|c|c|}
\hline & & \multicolumn{4}{|l|}{ Type of Scar } & \multirow[t]{2}{*}{ Statistical tests } \\
\hline & & Fibro-retractile & $\begin{array}{l}\text { Hypertrophicl } \\
\text { keloid }\end{array}$ & Normal & Total & \\
\hline \multirow[t]{4}{*}{ Initiallesion } & Decayingulcer & 91 & 52 & 9 & 152 & Chi2=2, I3; ddl=4etp=0,7I \\
\hline & Not ulcerated & 51 & 20 & 4 & 75 & \\
\hline & Scar & 10 & 7 & 0 & 17 & \\
\hline & Total & 152 & 79 & 13 & 244 & \\
\hline \multirow[t]{2}{*}{$\begin{array}{l}\text { Received } \\
\text { traitement }\end{array}$} & Medicated & 35 & 5 & 7 & 47 & Chi2 $=98,20 ; d d 1=6$ etp $=6.10-19$ \\
\hline & Medical-surgical & 16 & 29 & 4 & 49 & \\
\hline
\end{tabular}


Table Continued....

\begin{tabular}{llllll}
\hline & Type of Scar & & & \\
\cline { 3 - 5 } & & Fibro-retractile & $\begin{array}{l}\text { Hypertrophicl } \\
\text { keloid }\end{array}$ & Normal & Total \\
\hline Traditional & 15 & 2 & 0 & 17 \\
Total & 152 & 79 & 13 & 244
\end{tabular}

Table 4 Patient distribution according to the initial lesion and the neuro locomotor sequelae

\begin{tabular}{|c|c|c|c|}
\hline & \multicolumn{2}{|c|}{ Neuro-locomotor sequelae } & \multirow[t]{2}{*}{ Statistical tests } \\
\hline & Yes & No & \\
\hline & \multicolumn{3}{|c|}{ Amyotrophy } \\
\hline Decayingulcer & 97 & 36 & $C h i^{2}=I, I I$ \\
\hline Not ulcerated & 55 & 15 & $\mathrm{Ddl}=2$ \\
\hline \multirow[t]{2}{*}{ Scar } & 13 & 3 & $p=0,57$ \\
\hline & \multicolumn{3}{|c|}{ Joint Stiffness } \\
\hline Decayingulcer & 52 & 81 & $\mathrm{Chi}^{2}=2,24$ \\
\hline Not ulcerated & 20 & 50 & $\mathrm{Ddl}=2$ \\
\hline \multirow[t]{2}{*}{ Scar } & 6 & 10 & $p=0,36$ \\
\hline & \multicolumn{3}{|c|}{ Muscle Paresis } \\
\hline Decayingulcer & 53 & 80 & $\mathrm{Chi}^{2}=3,34$ \\
\hline Not ulcerated & 20 & 50 & $\mathrm{Ddl}=2$ \\
\hline \multirow[t]{2}{*}{ Scar } & 4 & 12 & $p=0,19$ \\
\hline & \multicolumn{3}{|c|}{ Sensitivity Disorder } \\
\hline Decayingulcer & 93 & 59 & Chi=2I,42 \\
\hline Not ulcerated & 56 & 19 & $\mathrm{Ddl}=4$ \\
\hline Scar & 10 & 7 & $p=0,0003$ \\
\hline
\end{tabular}

Table 5 Distribution of patients according to the treatment and neuro-locomotor sequelaes

\begin{tabular}{llll}
\hline & Neuro-locomotor sequelae & & $\begin{array}{c}\text { Statistical } \\
\text { tests }\end{array}$ \\
\hline & Yes & No & \\
\hline Medicated & 7 & 14 & Chi $^{2}=33,02$ \\
Medical-surgical & 41 & 20 & Ddl $=4$ \\
Medical-traditional & 13 & 6 & $\mathrm{P}=0,0000$ \\
Traditional & 13 & 2 & \\
Medical-surgical-traditional & 91 & 12 & \\
& Joint stiffness & & \\
Medicated & 0 & 21 & $\mathrm{Chi}{ }^{2}=18,07$ \\
Medical-surgical & 18 & 43 & $\mathrm{Ddl}=4$ \\
Medical-traditional & 7 & 12 & $\mathrm{P}=0,0012$ \\
Traditional & 5 & 10 & \\
Medical-surgical-traditional & 48 & 55 & \\
\hline
\end{tabular}


Table Continued....

\begin{tabular}{|c|c|c|c|}
\hline & \multicolumn{2}{|c|}{ Neuro-locomotor sequelae } & \multirow[t]{2}{*}{$\begin{array}{l}\text { Statistical } \\
\text { tests }\end{array}$} \\
\hline & Yes & No & \\
\hline & \multicolumn{2}{|c|}{ Amyotrophy } & \\
\hline Medical-surgical & 19 & 42 & $\mathrm{Ddl}=4$ \\
\hline Medical-traditional & 5 & 14 & $\mathrm{p}=0,0012$ \\
\hline Traditional & 3 & 12 & \\
\hline \multirow[t]{2}{*}{ Medical-surgical-traditional } & 50 & 53 & \\
\hline & \multicolumn{2}{|c|}{ Sensitivity disorder } & \\
\hline Medicated & 7 & 16 & $\mathrm{Chi}^{2}=2 \mathrm{I}, 42$ \\
\hline Medical-surgical & 46 & 21 & $\mathrm{Ddl}=4$ \\
\hline Medical-traditional & 12 & 13 & $p=0,0003$ \\
\hline Traditional & 9 & 7 & \\
\hline Medical-surgical-traditional & 85 & 28 & \\
\hline
\end{tabular}

Table 6 Patient distribution according to influence of rehabilitation on neurolocomotor sequelae

\begin{tabular}{llll}
\hline & \multicolumn{2}{l}{ Rehabilitation } & Statistical Tests \\
\cline { 2 - 3 } & Yes & No & \\
\hline Amyotrophy & 58 & 34 & Chi $^{2}=12,9$ I et $p=0,0003$ \\
Joint stiffness & 81 & 60 & Chi $^{2}=0,048$ et $p=0,47$ \\
Muscle paresis & 74 & 68 & Chi $^{2}=5,728$ et $p=0,01$ \\
Sensitivity disorders & 34 & $5 \mathrm{I}$ & Chi $^{2}=9,83$ et $p=0,00 \mathrm{I}$ \\
\hline
\end{tabular}

\section{Conclusion}

Patients with BU heal with severe sequelae. These cutaneous sequelae include fibro-retractile scars, hypertrophic scarring and/or keloids, muscular amyotrophy. Neuro-muscular sequelae are paresis and cutaneous hypoesthesia. About articular joint sequelae, it is stiffness and bone end Amputations. Those troubles persisted and/or worsened after returning home. The resulting reductions in capacity and participation limitations were diverse. Since the limbs are preferentially affected, these sequelae render their functions unsightly and also cause psycho-socio-professional and family problems.

\section{Acknowledgements}

We express our gratitude to all those who, from near or far, have contributed to the realization of this study, more specifically the community relays and the Buruli ulcer treatment center agents.

\section{Conflict of interest}

There is no conflict of interest related to the completion of this study.

\section{References}

1. Lehman L, Simonet V, Saunderson P. Ulcère de Buruli : prévention des incapacités (POD). 2006;3:35.

2. Toll A, Gallardo F, Ferran M, et al. Aggressive multifocal buruli ulcer with associated osteomyelitis in an HIV- positive patient. Clin Exp Dermatol. 2005;30(6):649-651.
3. Delaporte E, Savage C, Alfandari S, et al. Buruli ulcer in a zairian woman with HIV infection. Ann Dermatol Venereol. 1994;121(8):557-560.

4. Knipper $\mathrm{P}$, Ziliox R, Johnson RC, et al. Ulcère de buruli et chirurgie plastique au dispensaire. Ann chir plastesth. 2004;49(3):265-272.

5. Aguiar J, Stenou C. Buruli ulcers in rural areas of Benin: management of 635 cases. Med Trop. 1997;57(1):83-90.

6. Barker DJ. The distribution of buruli in uganda. Trans $R$ Soc Trop Med Hyg. 1972;66(6):867-874.

7. Ellen DE, Stienstra Y,Treelken MA, et al. Assessment of functional limitations caused by mycobacterium ulcerans infection: towards a Buruli ulcer functional limitation score. Trop Med Int Health. 2003;8(1):90-96.

8. Kanga JM, Kacou ED. Aspects épidémiologiques de l'ulcère de Buruli en Côte d'Ivoire : résultats d'une enquête nationale. Bull Soc PatholExot. 2001;94:46-51.

9. Ouattara D, Meningaud J P, Kaba L, et al. Les procédés de couverture cutanée des séquelles de l'ulcère de Buruli: à propos de 16 observations. Ann chirplastesth. 2003;48:13-19.

10. Kaloga M, Kourouma HS, Diabaté A, et al. Squamous cel carcinoma secondary to Buruli ulcer in West Africa. Ann Dermatol Venereol. 2016;143(1):16-20.

11. Debacker M, Aguiar J, Setonou C, et al. Buruli ulcer recurrence in benin Emerg Infect Dis. 2005;11(4):584-589.

12. Asiedu K, Raviglione MC, Scherpbier R. Ulcère de buruli: Infection à Mycobacteriumulcerans. 2000;1:10-52.

13. Kibadi K. Ulcère à Mu: Prise en charge chirurgicale dans 102 observations en République Démocratique du Congo. Med Trop. 2005;65:444-448.

14. Clancey JK, Dodge O, Lunch HF, et al. Mycobacterial skin ulcers in Uganda. Lancet. 1961;28(2):952-954.

15. Sopoh GE, Dossou A, Matilibou G, et al. Enquête de prévalence sur l'ulcère de Buruli dans les communes d'Allada, Toffo et Zè Bénin rapport, Bénin; 2006. p. 53

16. Josse R, Andre L, Zinsou C. Etude clinique et épidémiologique de l'ulcère chez le jeune au Benin. Cahier de santé. 1992;2(1):23-27.

17. Barker DJ. Epidemiology of Mu infection. Trans $R$ Soc Trop Med Hyg. 1973;67:43-50. 
18. Kadio R. Les ulcères cutanés à mycobactéries atypiques et leur traitement par la chirurgie plastique. Med Afr Noire. 1990;37(5):276-280.

19. Werf TSV, Ymkje S, Christian RJ, et al. Public health reviews: Mycobacterium ulcerans disease. Bulletin of the world health organization. 2005;83(10):785-791.

20. Adu EJ. Management of complications of Mycobacterium ulcerans disease : A three-years review. Int J Mycobacteriol. 2013;2(4):206-210.

21. Guifo ML, Essienne A, Ngo Nsoga M, et al. Surgical management of chronicwounds in a Buruli ulcer endemic area in Central Africa. World $J$ Surg. 2016;40(5):1041-1046.

22. Hans MA, Sossou R, Boco V, et al. Aspects radiologiques des atteintes osseuses de la maladie de Buruli. J AfrImag vol n³ Mai-Août ; 2003.
23. Houngbedji MG, Boissinot M, Bergeron GM, et al. Subcutaneous injection mycobacterium ulcerans causes necrosis, chronic inflammatory response and fibrosis in skeletal muscle. Microbes infect. 2008;10(1213):1236-1243.

24. Kpadonou GT, Houngbédji MG, Alagnidé E, et al. Health-related quality of life of adult patients healed from buruli ulcer in benin. $\mathrm{Br} J$ of $\mathrm{Med}$ \&Medicabl Res. 2015;6(1):88-98.

25. Kpadonou GT, Alagnidé E, Azanmasso H, et al. Psychosocio professionnal and familial becoming of formers Buruli ulcer patients in Benin. Ann Phys Rehabil Med. 2013;56(7-8):515-526. 